\title{
Gracián e Vieira: o lugar do "mistério"
}

\begin{abstract}
Alcir Pécora
Unicamp

Resumo: O ensaio investiga a aplicação do tópos do mistério na obra de dois jesuítas do século XVII, o português Antonio Vieira (1608-1697) e o aragonês Baltasar Gracián (1601-1658). Propõe que o seu emprego, em ambos os autores, afirma tanto a racionalidade inscrita no mundo como a sua dimensão necessariamente sensível. Um e outro aspecto articulam-se de modo a evidenciar a presença palpável, conquanto invisível, de Deus na história humana, o qual não fica diminuído, mas dignificado nela. Por fim, propõe que o lugar espesso em que a presença infinita de Deus se manifesta na matéria finita solicita a primazia do lugar do intérprete da matéria do mundo na hermenêutica da palavra divina.
\end{abstract}

Palavras chaves: Antonio Vieira, Baltasar Gracián, tópica, mistério, século XVII, barroco.

\footnotetext{
"Este mundo é um teatro; os homens as figuras que nele representam, e a história verdadeira de seus sucessos uma comédia de Deus, traçada e disposta maravilhosamente pelas idades de sua Providência." (Vieira, História do Futuro 156)

“Cuanto más escondida la razón, y que cuesta más, hace más estimado el concepto,

despiértase con el reparo la atención, solicítase la curiosidad, luego lo exquisito de la solución desempeña sazonadamente el misterio." (Gracián, Agudeza 1: 96)
}

O tópos do "mistério," aplicado por tratadistas e oradores do século XVII, fundase no postulado de uma natureza cujas espécies repõem uma substância infinita e 
invisível, análoga e proporcional à divindade. Enquanto sobreposição do infinito no finito, a proposição de uma "presença sem vista" tem sido interpretada, na história da cultura, como paradoxo e artifício gratuito, como efeito típico de uma época que se toma por "miracular" (Mandrou) e afeita a toda sorte de irracionalismos.

Entretanto, retomadas algumas de suas referências históricas, aqui exemplarmente atinentes ao emprego que delas é feito pelo jesuíta aragonês Baltasar Gracián (1601-1658) e pelo jesuíta português Antonio Vieira (1608-1697), é possível verificar-se que tal sobreposição misteriosa de um centro sem circunferência, que é puro Ser, a uma pequena esfera, domínio da falta e das imperfeições humanas, está fundada sobre uma racionalidade discursiva coerente em seus termos e ajustada ao discurso da igreja contrarreformista e militante de inspiração jesuítica. É o que se tentará argumentar neste ensaio.

Para começar pelo segundo autor mencionado, é possível dizer que a oratória sacra de Vieira evidencia um importante deslocamento na maneira de tratar a questão teológica da "união mística," referindo menos um raptus, no qual o homem é passivamente arrebatado até junto de Deus por obra da Graça, do que uma disposição da ação humana para instaurar no mundo uma vontade análoga à divina. No interior dessa apropriação de um tema contemplativo por uma disposição militante, pode-se entender que o lugar dos Sacramentos-e, exemplarmente, o do Mistério Eucarístico-assinale uma espécie de nó argumentativo em seus sermões.

Mas não apenas neles. A orientação inaciana está na base desse deslocamento. Conquanto o objetivo transcendente da militância católica permaneça decisivo, está claro que Santo Inácio de Loyola (1491-1556) pretendeu reduzir os atos de mortificação próprios dos regimes ascetas em favor de uma disciplina da vontade. No segundo capítulo da terceira parte das Constituições jesuíticas, dedicado ao tema da "conservação do corpo," está prescrito, por exemplo: “... como la solicitud demasiada en lo que toca al cuerpo es reprehensible, ansí el cuidado competente de mirar cómo se conserve para el divino servicio la salud y fuerzas corporales es loable, y deberían todos tenerle" (Inácio 507). E também se pode ler: "La castigación del cuerpo no debe ser inmoderada ni indiscreta en abstinencias, vigilias y otras penitencias exteriores y trabajos que dañan e impiden mayores bienes" (Inácio 509). 
A contrapartida ao abrandamento dos castigos é a redobrada atenção aos modos públicos de conversão, com destaque evidente para a oratória sacra, nos quais se crê efetivamente atualizar a presença de Cristo no mundo das imperfeições humanas. Pelo menos as dez primeiras regras que guardam o "sentido verdadeiro da Igreja militante," previstas por Santo Inácio ao final dos Exercícios espirituais, tratam diretamente da importância da prática litúrgica, cerimonial e sacramental para que se possa desenvolver entre os fieis um corpo concreto de gestos favoráveis à percepção da presença permanente de Cristo entre os homens:

\begin{abstract}
Alabar el confesar con sacerdote y el rescibir del sanctísimo ... alabar el oír misa a menudo, asimismo cantos, psalmos y largas oraciones en la iglesia y fuera della .... Alabar mucho religiones, virginidad y continencia ... alabar relíquias de sanctos, haciendo veneración a ellas, y oración a ellos: alabando estaciones, peregrinaciones, indulgencias, perdonanzas, cruzadas y candelas encendidas en las iglesias ... alabar constituciones cerca ayunos y abstinencias, así como quaresmas, quatro témporas, vigilias ... ; alabar ornamentos y edificios de iglesias; asimismo imágenes y venerarlas según que representan. (Inácio 287-88)
\end{abstract}

Nesta nova perspectiva, é importante notar que a própria matéria física ganha densidade sacra. Os sucessos e circunstâncias mais contingentes ganham um estatuto ontológico e teológico dúplice, de modo que tudo o que ocorre, assim como passa e desfaz-se, também sinaliza e revela a permanência. Pode-se dizer que certa espessura espiritual, constantemente atuante como Causa inscrita no mundo criado, comprime e altera a lei da matéria.

A via que se anuncia aqui refere, pois, um movimento muito particular: o que é da ordem da transcendência-logo, não determinada por qualquer essência particular, segundo a matriz tomista que retoma seu lugar central na ortodoxia desde meados do XVI—prevê espécies visíveis nas quais imprime a vibração do seu ato de ser. Outra maneira de referir o mesmo fenômeno é ressaltar o fato de que a natureza transcendente passa a ser ostensivamente assinalada por certos objetos e situações muito concretas, as quais, entretanto, nunca a revelam ou expõem inteiramente. O que fazem é anunciar que, simulando 
transparências, tais objetos são como véus, de modo que algo oculto existe naquilo mesmo que se dá a ver. Tal é a forma pela qual se compõe o lugar retórico de "mistério" no século XVII: há sempre o sinal manifesto de uma Coisa que, em si mesma, sem a mediação desse sinal, não se deixa ver; ao mesmo tempo, tudo o que esse sinal deixa ver é vestígio, insinuação da Coisa.

Entender a complexidade seiscentista do lugar retórico do mistério, no qual o divino tem uma demarcação sensível mas simultaneamente "fecha-se aos olhos" como parece supor sua etimologia (Prümm), obriga ainda a considerar a eficácia precisa que a ele se atribui numa economia de salvação. Sobretudo para um jesuíta como Vieira, a tópica do mistério não dissocia jamais a especulação sobre o Ser de Deus, raramente muito desenvolvida, da comunicação salvífica produzida por meio dela, esta sim, espetacularmente produzida. Ou seja, a forma do mistério se dá como uma manifestação do Verbo especialmente direcionada para o mundo das imperfeições humanas como expressão de uma generosidade Providencial.

É a função salvífica, voltada para o homem, que define a forma mais conveniente e eficaz dessa espécie de anúncio secreto. E isto porque, como argumenta Vieira no "Sermão das chagas de S. Francisco" (1672), a "obra sobrenatural" cuida sempre de usar os "instrumentos mais proporcionados aos efeitos" (Sermões 21:77). Portanto, a mobilização da tópica do mistério não se faz como glosa de teologia especulativa, mas como aplicação dos argumentos teológicos à missão apostólica. Acima de tudo, o que conta nela é a ação eficaz de conversão.

Essa mesma concepção persuasiva da forma misteriosa, mas com o acento posto não no apostolado, mas sim no efeito agudo que enseja, encontrase em outro jesuíta do século XVII, Baltasar Gracián. Em sua Agudeza y arte de ingenio (1642), logo após distinguir os tipos mais gerais da "agudeza," define aquela que se efetua mediante uma "ponderação misteriosa," a qual consiste em: “... levantar misterio entre la connexión de los extremos, o términos correlatos del sujeto, repito, causas, efectos, adjuntos, circunstancias, contingencias; y después de ponderada aquella coincidencia y unión, dase una razón sutil y adecuada, que la satisfaga" (1:89).

A proeminência dada a esse tipo de "artifício engenhoso" é justificada pelo prazer associado ao custo e à dificuldade de obtenção do bem: “... quien 
dice misterio, dice preñez, verdad escondida y recóndita, y toda noticia que cuesta, es más estimada y gustosa" (Agudeza 1:89). Mas se há disponibilidade para a apreciação de atributos enigmáticos e misteriosos, pois entretêm os sentidos e a inteligência, numa perspectiva teológica, sempre essencial aqui, não é possível desconsiderar o peso do "mundo" na restrição do "arbítrio" pessoal e na corrupção do "reto" desejo pelo "apetite," sensual e incontinente.

A solução de Vieira para esse paradoxo aparente é que Deus provê o mundo com sinais sensíveis de sua presença a fim de manter o desejo humano, considerado nas condições realistas de sua fragilidade e inconstância, orientado para a busca do Ser. O "mistério" é uma baliza eficaz a pontuar as "ocasiões" do arbítrio e a assinalar a orientação da vontade divina. Portanto, se há uma evidente relação entre a tópica do "mistério" e o aspecto sensível que ela supõe, há também entre ela e a variedade das circunstâncias sobre as quais incide.

Entre os autores de formação jesuítica, o lugar fundamental da "ocasião" define tanto o processo de escolha suposto no arbítrio, quanto o de julgamento e exculpação dos atos decorrentes dele. Esse tipo de proporção jesuítica, no qual o caso tem precedência na interpretação da doutrina, permite a Vieira criar no "Sermão de S. Roque" (1644) um aforismo decisivo para o entendimento do conjunto de sua obra: "Não sou de fazer mistérios dos acasos, mas folgo de fazer doutrina da ocasião" (Sermões 20:197). A fórmula admirável sintetiza, no domínio da oratória sacra, considerações análogas às de Gracián a propósito da "ponderação misteriosa." Por exemplo, no que toca à condenação do artifício gratuito: "Levantar el misterio donde no le hay es un helado desaire, porque da en vacío la ponderación" (Agudeza 264). É o mesmo para a declaração da importância decisiva das contingências na projeção do mistério, o que é radicalmente distinto de assumi-lo como obra do acaso: "Las contingencias son la ordinaria materia de los misterios; porque como pudieron variarse, el concurrir estas más que otras, ocasiona luego el reparo" (264). O que também se deixa ler na proposição: "La fuente destas ponderaciones misteriosas es la variedad y pluralidad de las circunstancias, suceder con estas, más que con otras: desta suerte, más que de aquella" (264).

Pode-se dizer que, de acordo com a perspectiva adotada pelos dois jesuítas, o tópos do "mistério" se articula no âmbito do caso, da ocasião e em 
oposição direta ao puramente casual, ao que não encontra uma razão oculta para as correspondências supostas ou advertidas. Do mesmo modo, opõe-se à fantasia, pois esta apenas projeta razões infundadas, isto é, sem fundamento no Ser e, portanto, em Deus.

A correta aplicação do lugar do mistério supõe um saber que adquire certificação ontológica, um documento de autenticação transcendental que apenas pode ser fornecido pelo exame detalhado das circunstâncias convenientes ao caso. O aforismo de Vieira exige que o "mistério" assinale a substância original teológica que se descobre nos casos-vale dizer, exige que seja "figura" da transcendência. Apenas dessa forma pode orientar o livre-arbítrio em meio à variedade atropelada do mundo, desenganada como "vaidade," "engano," "pó," "sombra," "zombaria" e "nada."

Antes de continuar nessa direção, vale lembrar que, em termos de ortodoxia católica, nenhuma matéria pode conter completamente a Deus, embora nenhuma matéria exista sem tê-lo como Causa. No que toca à hermenêutica neotomista, predominante no século XVII, que ressalta a relevância dos sentidos no processo cognitivo e salvífico do homem, é a "generosidade comunicativa" de Deus que o faz manifestar-se por meio de "sinais," que agem como auxiliares do "arbítrio" no atendimento à finalidade cristã da existência.

Entretanto, como é próprio da noção de arbítrio pensada catolicamente que demanda uma escolha de risco (onde não há risco de erro ou perdição, não há virtude no acerto), os próprios sinais estão carregados de perigo. Ao excitar os sentidos humanos e, por meio deles, os afetos e a imaginação, insinua-se a possibilidade diabólica de que os sinais inscritos materialmente sejam tomados como totalidade e não como anúncio, e, desse modo, sejam erradamente autonomizados de sua orientação final, esvaziados de sua busca essencial do Ser. A propósito, pode ser útil a referência a um oratoriano francês, Jean-François Senault (1599?1672), cujo tratado De l'usage des passions (1641), ao comentar o "movimento do apetite sensitivo," que está necessariamente presente em toda paixão, afirma:

Ce mouvement est causé par l'imagination, qui étant remplie des especes qu'elle a receuës de tous le sens, sollicite la passion, et luy découvre les beautez ou les laideurs des objets qui la peuvent émouvoir: car c'est elle qui cause tout 
le ravage: L'appetit sensitif a tant de deference pour elle, qu'il suit toutes ses inclinations; Pour peu qu'elle soit agitée elle entraîne toutes les passions, elle excite les tempestes, comme les vents élevent les flots, et l'ame seroit paisible en sa partie inferieure, si elle nétoit émeuë par cette puissance

Assim é que, afinados por esse mesmo diapasão de abundância comunicativa, excitação passional e risco de escolha, muitos pensadores católicos do período tomam os processos de manifestação divina no mundo em dupla mão: tão logo levantam sinais na matéria de uma escrita transcendente, julgam igualmente necessário interrogar o fundamento da "autoridade" de seus intérpretes. É também o caso de Vieira:

Que historiador há ou pode haver, por mais diligente investigador que seja dos sucessos presentes ou passados, que não escreva por informações? E que informações há de haver que não vão envoltas em muitos erros, ou da ignorância, ou da malícia? Que historiador houve de tão limpo coração e tão inteiro amador da verdade, que o não inclinasse o respeito, a lisonja, a vingança, o ódio, o amor, ou da sua, ou da alheia nação, ou do seu ou de estranho príncipe? Todas as penas nasceram em carne e sangue, e todos na tinta de escrever misturam as cores do seu afeto. (História 146)

Segue-se daí a necessidade de legitimação do intérprete, subordinada ao correto domínio e aplicação de uma ciência de signos, a qual demanda tanto o aval da hermenêutica canônica, como o da competência na interpretação dos sucessos atuais da história prática, coletiva e institucional. Trata-se, portanto, de uma ciência dos signos ajustada ao caráter jurídico da Contrarreforma, cujo saber tende a alegar a "investidura" do intérprete na sede das hierarquias eclesiásticas. São Paulo fornece a matriz dessa exigência de certificação do intérprete, quando condiciona o valor das profecias ao reconhecimento de que ele fala por Autoridade divina em 1 Coríntios 14: 37-40:

Si quis videtur propheta esse aut spiritalis cognoscat quae scribo vobis quia Domini sunt mandata; si quis autem ignorat ignorabitur. Itaque fra- 
tres aemulamini prophetare et loqui linguis nolite prohibere. Omnia autem honeste et secundum ordinem fiant.

[Se algum crê ser profeta ou (pessoa) espiritual, reconheça que as coisas que vos escrevo são mandamentos do Senhor. Se algum, porém, o ignorar, será ignorado. Por isso, irmãos, desejai ardentemente o dom de profetizar, e não proibais o uso do dom das línguas. Mas faça-se tudo convenientemente e com ordem.]

O passo, lido em chave contrarreformista é frontalmente hostil ao "livre-exame" luterano, no qual a comunicação entre Deus e o fiel se passa num espaço íntimo e exclusivamente espiritual. Em termos mais abrangentes, expressa a exigência de articulação entre o aspecto secreto existente no sinal sensível e o domínio autorizado da hermenêutica capaz de interpretá-lo adequadamente como anúncio. Vale dizer, o lugar retórico do "mistério" introduz também a prescrição da Autoridade que certifica a exegese das coisas e estanca a sangria da proliferação de vozes fantásticas na variedade confusa do mundo.

Há, portanto, um movimento complexo na aplicação da tópica do mistério, tal como efetuada pelos autores católicos do século XVII: trata-se de um mostrarse que é igualmente esconder, de uma evidência que acena para o que se oculta. Essa posição pode ser encontrada mesmo em autores que não têm simpatia pelos jesuítas e em gêneros letrados muito diversos dos da Oratória sacra ou dos tratados de teologia. Por exemplo, ao escrever à filha a propósito da qualidade de certo "Sermão da Paixão" pregado pelo jesuíta Louis Bourdaloue (1632-1704), Mme. de Sévigné (1626-1696) proclama: “Ah! Bourdaloue! Il fit, à ce qu’on m’a dit, une Passion plus parfaite que tout ce quon peut imaginer; cétait celle de l'année passée, qu'il avait rajustée, selon ce que ces amis lui avaient conseillé, afin qu'elle fut inimitable" (1: 207). Para então arrematar, rigorosamente: "Comment peut-on aimer Dieu, quand on nentend jamais bien parler de lui?" (1: 207). Quer dizer, a qualidade sensível da elocução oratória passa a ser considerada decisiva para a convicção da matéria mística a que remete. $\mathrm{O}$ amor por Deus decorre ou mesmo depende do efeito persuasivo gerado pelo sermão que o comenta. Ao louvá-lo com belas palavras, ao falar bem dele, age como um performativo que atualiza o Bem que lhe é próprio. O domínio perfeito da língua torna-se causa eficiente da fé. 
Não é um sentimento muito distante deste que leva vários tratadistas do século XVII a adotar uma Ratio organizada como acúmulo de regulamentos precisos e de artifícios engenhosos para todo tipo de assunto, desde os referidos pelas solenes "artes de reinar" e "espelhos de príncipes," ou aqueles prescritos nos manuais de prudência, de falar e de calar, de toda sorte de decoro, até os prescritos em "cartas de guias" para casados. A malha quase jurídica dessas disposições parece garantir não a ausência de equívocos nem a auto-evidência dos processos jurídicos (pois é bem o contrário que se alcança: quando se multiplicam as prescrições, todo o prescrito admite licença e pode ser que venha a parar no contrário de si mesmo), mas a fiança de que age no mundo uma inteligência sutil que tudo penetra, que percorre a cascata de normas, insinua a vertigem da traição demoníaca, e finalmente, se chega a ultrapassá-la, ajusta razão e fé, persuasão e verdade.

A via oblíqua aberta pelo lugar do mistério também pode produzir um efeito dramático, isto é, a tensão necessária ao "desempenho" de uma "razão oculta," que interfere na aparência dos objetos nos quais se instala, ainda que os transcenda. E convém acentuar a ideia de performance associada ao termo "desempenho," como se nota, exemplarmente, em Gracián. Ao falar da "ponderação misteriosa," especifica: "Añade esta especie de agudeza, al artificio de la ponderación misteriosa, la dificultad entre la connexión de los extremos, digo de los términos correlatos; y después de bien exprimida la dificultad, o discordancia entre ellos, dáse una razón, que la desempeñe" (Agudeza 268).

Significa, como ficou dito anteriormente, que o gosto engenhoso e intelectualista da verdade "difícil" está suposto na propriedade persuasiva da tópica do "mistério." Contudo, a eficácia da forma encoberta e complexa não se esgota em ser agradavelmente convincente, uma vez que a "razão oculta," em última instância, sempre tem causa na natureza divina. Aqui, retirar o horizonte místico da ideia de "mistério" representa uma perda irreparável para a interpretação de sua importância para a pregação seiscentista. No sentido contrário, para precaver-se dessa perda, parece adequado reverter a noção para o seu emprego nas Escrituras: “... sed loquimur Dei sapientiam in mysterio quae abscondita est quam praedestinavit Deus ante saecula in gloriam nostram, quam nemo principum huius saeculi cognovit....” ‘... mas pregamos a sabedoria de Deus no mistério, que está 
encoberta, e que Deus predestinou antes dos séculos para a nossa glória, a qual nenhum dos príncipes deste século conheceu....' (1 Cor. 2:7-8).

Vale dizer, a elocução engenhosa, aguda, dificultosa acomoda-se à lição paulina de "pregar no mistério," o que tem como decorrência imediata a tarefa de interpretar na vida insciente do homem e das sociedades os sinais sábios de Deus. Dito de outro modo, a busca de relações ocultas entre objetos extremos é um gesto intelectual ajustado ao processo alegórico infuso nas coisas criadas pelo Criador delas.

Da mesma maneira, é possível dizer que a preceptiva seiscentista da "agudeza" está ajustada à concepção cristã da "alegoria figural," que interpreta a orientação providencial inscrita nas ocasiões da história. O passo é crucial. Para esclarecê-lo, pode-se contrapô-lo a outro, da História do Futuro, no qual os artifícios conceituosos são pensados como "figura" da arte enigmática e codificada da Providência:

E assim como o primor e subtileza da arte cómica consiste principalmente naquela suspensão de entendimento e doce enleio dos sentidos, com que o enredo os vai levando após si, pendentes sempre de um sucesso para outro sucesso, encobrindo-se de indústria o fim da história, sem que se possa entender onde irá parar, senão quando já vai chegando e se descobre subitamente entre a expectação e o aplauso, assim Deus, soberano Autor e Governador do Mundo e perfeitíssimo exemplar de toda a natureza e arte, para maior manifestação de sua glória e admiração de sua sabedoria, de tal maneira nos encobre as cousas futuras, ainda quando as manda escrever primeiro pelos profetas, que nos não deixa compreender nem alcançar os segredos de seus intentos, senão quando já têm chegado ou vão chegando os fins deles, para nos ter sempre suspensos na expectação e pendentes de sua Providência. (156-57)

O mesmo oficio artístico da Providência, que cria um enredo industriosamente encoberto para suspender e enlevar entendimentos e sentidos até o desfecho dos fins dela, pode ajudar a entender a centralidade dos Sacramentos na propaganda católica do período. Por meio deles, a Igreja da Contrarreforma produz 
o fenômeno da multiplicação da presença salvífica do Cristo, a qual, exatamente porque está "encoberta," pode manifestar-se vertiginosamente em coisas, lugares e ocasiões muito diversas. Por exemplo, no "Sermão do Santíssimo Sacramento" (1669), Padre Vieira compara a presença multiplicada de Cristo no mistério eucarístico às muitas estrelas que, à noite, fazem as vezes de Sol:

Não debalde instituiu Cristo o Divino Sacramento de noite, quando, por uma presença que nos levou da vista nos deixou muitas à fé. Mete-se o sol no ocidente, escurece-se o mundo com as sombras da noite, mas se olharmos para o céu, veremos o mesmo sol multiplicado em tantos sóis menores quantas são as estrelas sem-número, em que ele substitui a sua ausência, e não só se retrata, mas vive. (Sermões 5:101)

A mesma eficácia da disseminação da presença do Ser na multiplicidade das espécies do mundo está descrita no "Sermão de Santo Antônio" (1653), quando os sacramentos tornam-se uma "extensão da Encarnação": “... os teólogos, como S. João Crisóstomo, chamam ao mesmo Sacramento extensão da Encarnação, porque a divindade comunicada na Encarnação a uma só humanidade, no Sacramento a estende Cristo e comunica a todos os homens" (Sermões 20:339).

A amplitude alcançada por meio dos sacramentos é encarecida também como uma quotidianização da presença divina na vida humana, e, em especial, na vida clerical. Assim argumenta Vieira, no "Sermão de S. João Batista" (1644), a ponto de dar "vantagem" ao amor de Cristo demonstrado na Eucaristia sobre o da Paixão: "Esta é a vantagem que leva em Cristo o amor que nos mostrou no Sacramento ao amor que nos mostrou na cruz. Na cruz morreu uma vez, no Sacramento morre cada dia; na cruz deu a vida, no Sacramento perpetuou a morte" (Sermões 13:191). Ainda, no que diz respeito à eficácia da tópica do mistério, pode-se dizer que ela é especialmente amplificada pela via do Sacramento, que constitui o cerne de várias linhas de ponderação dos sermões jesuíticos. Muito além dos casos em que refere práticas pias, deveres religiosos e rituais litúrgicos, o Sacramento se projeta sobre as instituições do Estado cristão, ganhando caráter nitidamente político, bem como sobre a 
história escatológica do homem, quando toma acentos especulativos e proféticos. Então, o corpo moral e político do Estado é concebido como domínio apto à manifestação da vontade transcendente, seja esta considerada como comunicação de uma "política cristã" a ser adotada no tempo presente, seja como anúncio de um futuro à espera de sua atualização na história.

Aqui, um reparo. É corrente afirmar-se que os autores da Contrarreforma propuseram uma interação contínua entre a Igreja e o "mundo," de tal modo que a primeira acaba por tomar um aspecto secularizado. No entanto, basta avaliar tal interação à luz do lugar do mistério, para ficar claro que não se trata disso. Ao contrário, se todo o processo da interação Igreja-Mundo, e mesmo da Igreja-Estado está assentado sobre a aplicação da presença da divindade no cerne do mundo político, então não se trata de secularização da Igreja, mas de sobrenaturalização do Estado.

No âmbito dos pensadores católicos, o Estado não se concebe jamais como domínio autônomo de política ou de operação de uma razão laica de governo, mas sim como objeto por excelência de teologia política-ou de uma "política do Céu," para referir a colorida expressão de Vieira, no "Sermão da Terceira Dominga do Advento" (1644) (Sermões 13: 388). Em outros termos, Jean-François Courtine confirma essa ideia ao afirmar que as monarquias centralizadas do século XVII devem à Teologia, antes de qualquer outro domínio, a sua primeira forma acabada:

\footnotetext{
... la première forme achevée-celle-là même que lui envieront longtemps justement les Etats naissants-d'une monarchie absolue, bureaucratisée et centralisée, puisque lui seul pouvait toujours, et en vertu de son principele Principe par excellence-assurer une assise véritablement inébranlable à lexercice de sa puissance. (92)
}

Pela mesma razão, para Courtine, não se sustenta a tese da origem secular do Estado absolutista moderno:

Ce qui caractérise au premier chef la genèse de l'État moderne, ce n’est pas
en effet d’abord la sécularisation des doctrines ecclésio-ou théologico-po- 
litiques-sécularisation qui aboutirait finalement à détacher la puissance publique de son empreinte ecclésiale ou sacramentelle, à la libérer de sa subordination aux fins de la Cité de Dieu, à la dresser dans son auto-suffisance hors de de 'l'idéologie' politique médiévale. Non! Ce qui nous paraît beaucoup plus important, et significatif, que ce processus indiscutable d'auto-affirmation, c'est au contraire la détermination strictement théologique de cette nouvelle figure de l'État absolu: l'absolutisation-enjeu ultime de la revendication d'hoirie, du conflit pour le principe-passe nécessariament et prioritairement par une re-sacralisation de l'État. (96)

Não é difícil ver que a sacralização do Estado, com vistas à legitimação do poder absoluto do Príncipe no Ser do Princípio, está contemplada na tópica do mistério, que projeta a forma encoberta do divino sobre a organização política do mundo. Mas há uma importante distinção a ser feita. No âmbito do lugar do mistério, tal projeção não tem o Príncipe como beneficiário direto dela, mas sim a natureza da res publica ou o Corpo Político do Reino. Por meio dessas mediações, ainda interpretadas pela Igreja e não pelo Soberano Nacional, prevê-se uma concomitância substancial entre as ordens transcendente e histórica, ainda quando não haja semelhança aparente entre elas.

Mas não apenas a questão da origem do Estado reforça os argumentos sobre a centralidade do lugar do mistério na Teologia Política católica. Ao considerar a Ratio capaz de ordená-lo e colocá-lo em funcionamento, depara-se com uma noção de Estado muito distinta das formulações coetâneas que pretendiam laicizá-lo, isto é, torná-lo "ímpio," por obra de um diabólico amálgama luterano-maquiavélico (Skinner 2:143). De fato, a considerar que Maquiavel desprovidencializa o Estado (Maravall), e que, dessa maneira, retira-lhe a função teleológica, a tópica do mistério aplica-lhe atributos contrários. Tratase aqui de descobrir nas ações e sucessos fundamentais do Estado cristão o enredo providencial que opera neles.

Se para os chamados "políticos" ou "maquiavélicos," o Estado é um artifício criado para exclusivo exercício do poder, para os neotomistas não é possível desvinculá-lo da lex naturalis, implantada no mundo pelo ato mesmo da Criação. Se, no âmbito do maquiavelismo, a política do Estado se ordena sobre 
a "separação" da esfera religiosa, para os católicos, ambos permanecem orientados por uma destinação comum.

Richard Morse entende a desprovidencialização maquiavélica-e ainda mais a de Hobbes-como desfecho lógico de um método que os leva a reunir exemplos variados de épocas e contextos muito diferentes a fim de constituir um modelo artificial de Estado, que abdica da "legitimação histórica para um papel providencial" (63). No caso dos autores contrarreformistas, tudo se passa inversamente. A ideia de artifício político é igualmente válida, mas tem o pressuposto contrário, que confere harmonização natural, não tirânica ou imaginária, entre a vontade da coletividade e a do Príncipe no todo ordenado do Estado.

Permanece válida a ideia do artifício como cálculo de poder ou, enfim, como "razão de Estado" a ser considerada pelo Príncipe cristão em sua política de estabelecimento do Bem Comum, apenas que esse cálculo não pode ser dissociado da santidade de seus fins e das injunções da reta razão. Ou seja, a ação política do Estado cristão necessariamente repõe a sua missão co-participativa nos desígnios de Deus para a história.

Obviamente tal reposição não implica em anuência antecipada dos autores católicos à política praticada pelo Estado. Historicamente, pode bem suceder que o Príncipe ou as disputas fratricidas entre as ordens do Reino conduzam-no a uma prática contrária ao Bem Comum e à atualização providencial, mas a questão é outra: trata-se aqui de pressupor uma substância divina inscrita misteriosamente no mundo, que o dispõe para a descoberta progressiva do código finalista da Providência. Ou seja, a missão providencial da política está naturalmente na base da ideia de Estado, mas a prática política, no presente, entregue às imperfeições e más escolhas dos homens, está ainda aquém de si mesma como instrumento capaz de atualizar a presença divina na história.

Tal concepção de política, na qual, orientados para o fim providencial, Deus e os homens podem ajustar-se numa vontade co-participativa, postula uma potência da história a ser atualizada no futuro, mas não nega a crise do presente. No limite, é possível pensar o Estado como uma latência do futuro no presente. $\mathrm{O}$ tempo presente o sinaliza, mas não o contém, nem pode ser identificado com a Causa final dele. Dito de outra maneira, o tópos do mistério tem de prever a diferença entre história e Providência assim como prevê que tal 
diferença é apenas etapa de uma superação histórica. A diferença entre Mundo e Providência torna-se aparência de uma analogia ou co-participação que não poderia ser descoberta sem o mergulho nas diferenças do mundo. Quando se fala em Mundo e Providência, deve-se entender que um é a face, mais ou menos opaca, mais ou menos alterada e ainda em alteração, que o Outro deixa exposta (Morse 32).

Quando a história é interpretada pela tópica do mistério, não se supõe que as razões históricas sejam autônomas, assim como não se supõe que sejam apenas fantasia: supõe-se que sejam sinal do Real cuja Verdade não se esgota nelas. Por indiferentes ou diferentes que os acontecimentos do mundo possam parecer em relação à vontade de Deus, permanecem sustentados por um "efeito" dela, cuja substância oculta solicita a especulação a respeito de seus sinais. E são tais sinais toda a orientação disponível aos homens viventes, dotados de intelecto finito. Donde se segue o vasto louvor dos que os sabem ler. Assim se admirava Critilo, personagem do Criticón de Gracián: "Pero, ¡qué gran arte aquella del descifrar!" (Obras completas 898).

Quando a decifração surge no âmago do lugar retórico do mistério, repõe-se imediatamente a questão da disputa pela legitimidade de seu intérprete, o que está no diapasão jurídico da Contrarreforma. Mas há também outra exigência que se faz ao intérprete, que não diz respeito apenas à ciência ou doutrina, mas ao repertório da experiência, aos "trabalhos" da vida. A exegese, aqui, toma foros de aventura; seu autor, a investidura de um bravo que se lança a uma empresa colossal. Gracián o adverte da seguinte maneira: “... nada es cuanto se ha dicho con lo que queda por decir...” (Obras completas 898). E ainda: “... todo cuanto hay escrito en todas las artes y ciencias no ha sido más que sacar una gota de agua del oceano del saber....” (898).

Enfim, trata-se de um mundo que apenas se compreende numa narrativa teleológica, no qual os eventos, imperfeitos mas perfectíveis, não alcançaram “... ni aun a la mitad de lo que pueden subir...” (Obras completas 898). Então é possível compreender-se que o verdadeiro "herói” do tempo do mistério seja o exegeta das coisas sobre os signos embaixo das coisas etc.: o Veedor de todo (899). Ainda no Criticón, o "herói" pinta o seguinte autorretrato: "Yo llego a ver la misma sustancia de las cosas en una ojeada, y no solos los accidentes y 
las aparencias, como vosotros; yo conozco luego si hay sustancia en un sujeto, mido el fondo que tiene, descubro lo que tira y dónde alcanza, hasta dónde se extiende la esfera de actividad, dónde llega su saber y su entender, cuánto ahonda su prudencia" (899).

Em Vieira, a qualidade do intérprete nesta epopeia sacra mede-se menos pela faculdade de vidente do que pelo ofício de historiador do que ainda não tem história. O desempenho da razão oculta que permitirá responder adequadamente à estratégia do mistério está reservado à escrita rigorosa que revela o "encoberto" por meio da análise e da analogia do sensível, do material, do historicamente circunstanciado:

Os profetas não chamaram história às suas profecias, porque não guardam nelas estilo nem leis de histórias: não distinguem os tempos, não assinalam os lugares, não individuam as pessoas, nem seguem a ordem dos casos e dos sucessos, e quando tudo isto viram e tudo disseram, é envolto em metáforas, disfarçado em figuras, escurecido com enigmas e contado ou cantado em frases próprias do espírito e estilo profético, mais acomodadas à majestade e admiração dos mistérios, que à notícia e inteligência deles. (História 47)

E arremata, em favor da investigação acomodada às leis da história que, apenas ela, deverá "correr a cortina aos maiores e mais ocultos segredos deste mistério" (45):

E porque nós, em tudo o que escrevemos, determinamos observar religiosa e pontualmente todas as leis da história, seguindo em estilo claro e que todos possam perceber, a ordem e a sucessão das coisas, não nua e secamente, senão vestidas e acompanhadas das suas circunstâncias; e porque havemos de distinguir tempos e anos, sinalar províncias e cidades, nomear nações e ainda pessoas (quando o sofrer a matéria), por isso, sem ambição nem injúria de ambos os nomes, chamamos a esta narração história e História do Futuro. (47) 
O tópos do mistério, portanto, nesses autores jesuítas do século XVII, não nega o racional como não nega o sensível. Ao contrário, dignifica-os com a presença de um Deus "imenso e invisível" que não sofre "menoscabo de sua grandeza" quando limitado em "tão pequena esfera," como o diz Vieira no "Sermão do Santíssimo Sacramento" (1645) (Sermões 1: 138-40). Mas essa mesma "pequena esfera," habitada por um Deus, é demasiado espessa para a inteligência do homem. Aquele que a deseja conhecer está como argonauta solitário, lançado temerariamente ao mar:

Sós e solitariamente entramos nela (mais ainda que Noé no meio do dilúvio), sem companheiro nem guia, sem estrela nem farol, sem exemplar nem exemplo. O mar é imenso, as ondas confusas, as nuvens espessas, a noite escuríssima; mas esperamos no Pai dos lumes (a cuja glória e de seu Filho servimos), tirará a salvamento a frágil barquinha: ela com maior ventura que Argos, e nós com maior ousadia que Tífis. (Sermões 1: 138-40)

O pressuposto da aventura do intérprete é, portanto, que o visível necessariamente signifique mais do que dá a ver, ou, de outra maneira, que o "mistério" é o único significante verossímil de um sentido verdadeiro. Assim, a "frágil barquinha" do intérprete logrará romper a nuvem que há em meio a um mar tumultuado de coisas e signos, a fim de atender ao chamado das "maravilhas de seus mistérios," estes que luzem, aflitos, para desvendar-se. 


\section{Obras Citadas}

Courtine, Jean-François. "L'héritage scolastique dans la problématique théologico-politique de lâge classique." L'État baroque: Regards sur la pensée politique de la France du premier XVIIe siècle (1610-1652). Ed. Henry Méchoulan. Paris, Vrin, 1985. 90-118. Print.

Gracián y Morales, Baltasar. Agudeza y arte de ingenio. 2 vols. Ed. Evaristo Correa Calderón. Madrid: Castalia, 1969. Print.

Inácio de Loyola, Santo. Obras completas. Madrid: Católica, 1982. Print.

Mandrou, Robert. Le Baroque européen: mentalité pathétique et révolution sociale. Paris: Colin, 1960. Print.

Maravall, José Antonio. La philosophie politique espagnole au XVIIe siècle dans ses rapports avec l'esprit de la Contre-Réforme. Paris: Vrin, 1955. Print.

Morse, Richard. O Espelho de Próspero. Trad. Paulo Neves. São Paulo: Companhia das Letras, 1988. Print.

Prümm, Karl. "Mystery." Encyclopedia of Biblical Theology. 3 vols. Ed. Johannes B. Bauer. Trad. Joseph Blenkinsopp. London : Sheed and Ward, 1970. 2: 598-611. Print.

Senault, Jean-François. De l'usage des passions. 1641. Paris: Fayard, 1987. Print.

Sévigné, Madame de. Correspondance. 3 vols. Ed. Roger Duchêne. Paris: Pléiade. 1973-78. Print.

Skinner, Quentin. The Foundations of Modern Political Thought. 2 vols. Cambridge: Cambridge UP, 1978. Print.

Vieira, Antônio. História do futuro. Ed. Maria Leonor C. Buescu. Lisboa: Imprensa Nacional/ Casa da Moeda, 1982. Print.

—. Sermões. 24 vols. São Paulo: Editora das Américas, 1957. Print.

Alcir Pécora é professor titular de Teoria Literária da Unicamp. Autor de Teatro do Sacramento (1994), Máquina de Gêneros (2001) e As Excelências do Governador (2002). Organizador de várias obras de Vieira, entre elas: A Arte de Morrer (1994), Escritos Históricos e Políticos (1995), Sermões I e II (2000-2001) e Índice das Coisas Mais Notáveis (2010). Editor técnico de O Cortesão, de Baldassare Castiglione; Galateo, de Giovanni Della Casa; Da Infinidade do Amor, de Tullia D’Aragona; A Dissimulação Honesta, de Torquato Accetto, entre outras. Organizador das Obras Completas de Hilda Hilst e de Roberto Piva. 